\title{
FRICTIONAL BEHAVIOUR OF THIN TIN FILMS WITH A COPPER INTERLAVER
}

Generally, the purpose of the study is to know the effect of temperature during tin-films deposition on frictional behaviour and lifetime of a tin layer with copper interlayer. In a recent study an experimental approach was performed to investigate the effect of a copper interlayer thickness on frictional behaviour of thin films. In this experiment, copper of $2 \mu \mathrm{m}$ thickness was deposited between the steel substrate and tin films of $1 \mu \mathrm{m}$ and $2 \mu \mathrm{m}$ thicknesses in vacuum environment without and with the heating of the substrate up to $300{ }^{\circ} \mathrm{C}$. The friction tests were performed to determine the friction coefficient and lifetime of lubrication capability.

\section{Introduction}

Technological use of many tribology products or tribological systems depends on adequate control of friction mechanisms between elements of tribological system consisting of two or more materials. Studies on the surface design, surface engineering, and tribology of coatings and layers have shown that friction and wear of these materials depend significantly on various combinations of materials and environmental conditions.

Micro-tribological phenomena are presently widely investigated. New technologies designed to accomplish the tasks of today and future have also brought about new tribological issues, e.g. efficient drive of machines with micro-tribological joints is limited by power consumption due to friction. The limits of traditional liquid and gaseous lubricants underline the need to use different lubricants for investigation of micro-tribological behaviour of contacting surfaces. In the process of friction and wear thin films, for which the hard substrate keeps up its role, are used in this work. The term thin film refers to a coating of a measurable thickness of up to $2.0 \mu \mathrm{m}$. With development of new coating techniques for industrial applications, the significance of thin film lubricants is growing. Such lubrication is commonly used when fluid lubricant could not fulfil its tasks because of high temperature or high vacuum. Other areas of applications which influenced fast innovation of lubricating methods are in the field of aerospace, whole computer media branch, mechatronics and micro machines, where the use of hightech has become irrevocable. Coatings provide low friction and/or low wear and are often used in a wide range of temperatures, in different environments, including vacuum, usually at low loads and low sliding speeds. The most successful applications enable the reduction of a friction coefficient within a range of two or more order of the magnitude and also lower the wear. [1], [2], [3], [4].

\section{Experimental Procedures}

\subsection{Friction Test Equipment}

The equipment used to measure frictional force for a ball slider on a flat surface during experiments under low loads is presented schematically in Fig. 1. The friction test unit was assembled in a vacuum chamber, which was placed on a pneumatic damped table. The vacuum chamber allowed to examine friction behaviour of the tested pairs under different environmental conditions.

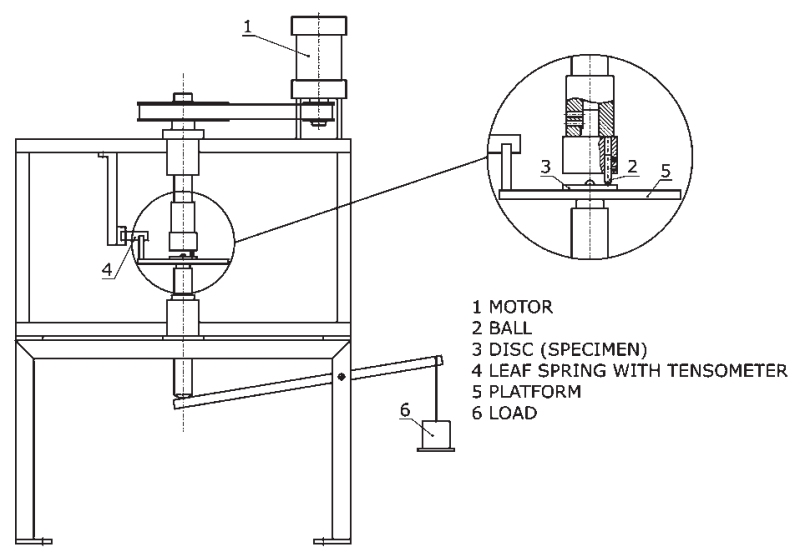

Fig. 1 Friction test apparatus

Friction experiments were carried out in vacuum of $10^{-5} \mathrm{~Pa}$ order. The stainless steel ball of a $3 \mathrm{~mm}$ diameter was fixed on the tip of the holder. The holder was arranged coaxially in a diameter

\footnotetext{
* Martin Komlossy ${ }^{1}$, Marián Dzimko, Yoshinori Takeichi², Masao Uemura ${ }^{2}$

${ }^{1}$ Faculty of Mechanical Engineering, University of Žilina, Univerzitná 1, SK-010 26 Žilina, E-mail: martin.komlossy@fstroj.utc.sk

${ }^{2}$ Toyohashi University of Technology, Department of Mechanical Engineering, Tempaku-cho, Toyohashi-shi, Aichi, 441 8580, Japan
} 
of $20 \mathrm{~mm}$ and the ball rotated on a coated disk specimen with a controlled sliding speed of $8 \mathrm{~mm} / \mathrm{sec}$. The load of $100 \mathrm{~g}$ applied to the ball resulted in normal force of $1 \mathrm{~N}$. The resulted friction forces were measured with a strain gauge placed on a leaf spring. The endurance life friction experiment continued until the tin film broke down. The criterion defining the break down of the film was marked by a sudden or substantial increase in the calculated and measured friction coefficient.

\subsection{Temperature Measurement of Substrate}

In recent experiments the temperature was measured with a thermocouple attached close to the substrate. There was a hypothesis that the real temperature of the substrate depending on the place of measurement is different from the one showed by the thermocouple. To verify this hypothesis a preliminary testing was undergone. The heater attached to the top of the deposition chamber (Fig. 2) was used for heating. The heater crystal was situated direct above the substrate. The temperature of specimens was measured according to the following procedure:

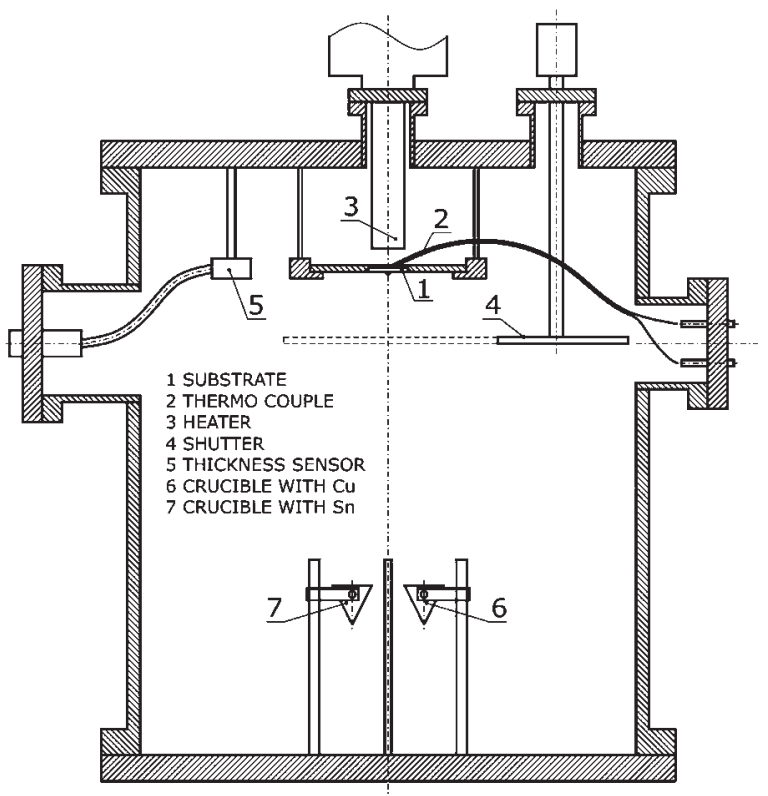

Fig. 2 Film deposition chamber

\section{For the first case}

The temperature of the heated specimen side was measured. The specimen substrate was heated continuously up to $300{ }^{\circ} \mathrm{C}$ and this temperature remained unchanged for the next 3 hours. Figure 3 shows that the temperature difference measured at two points, i. e. in the margin and in the centre of the substrate, is not significant. So, it can be assumed that there is no remarkable effect on the measurement accuracy of the thin film deposition if the thermo- couple is placed in the margin or in the centre of the specimen substrate.

\section{For the second case}

The temperature was measured on both sides of the specimen. Two methods for the heating of the specimens were applied.

For the first method, the so-called programmed consistent heating method was chosen. The upper side of the substrate was heated to $100{ }^{\circ} \mathrm{C}$ and remained at this temperature for 30 minutes, then the temperature was increased to $200^{\circ} \mathrm{C}$ and, again, remained unchanged for the next 30 minutes. Later the temperature was increased to $300{ }^{\circ} \mathrm{C}$ and was kept unchanged for 30 minutes (Figure 4).

For the second method, the upper side of the substrate was heated up to $300{ }^{\circ} \mathrm{C}$ and kept unchanged for 3 hours (Figure 5). The same procedure was repeated for the temperature of $400{ }^{\circ} \mathrm{C}$ (Figure 6).

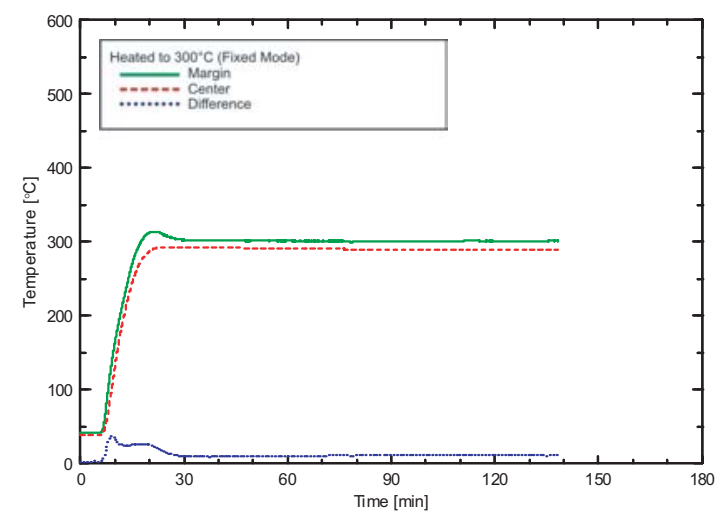

Fig. 3. Temperature in the margin and in the centre of specimen

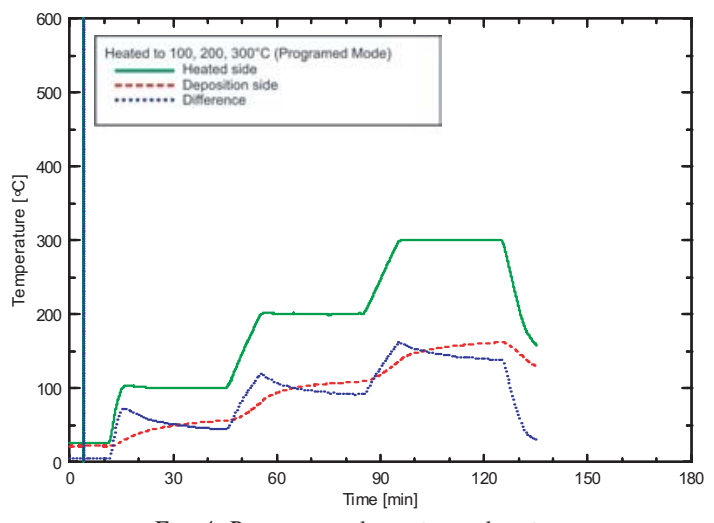

Fig. 4. Programmed consistent heating

For both methods the temperatures on the heated and deposition sides were measured. The results show that the temperature 
on the deposition side is nearly by $50 \%$ lower when compared to the temperature on the heated side. Accordingly, it can be assumed that, in the case of deposition with heating up to $300^{\circ} \mathrm{C}$ measured on the heated side, the real temperature of the substrate on the deposition side will reach the temperature of only $180^{\circ} \mathrm{C}$.

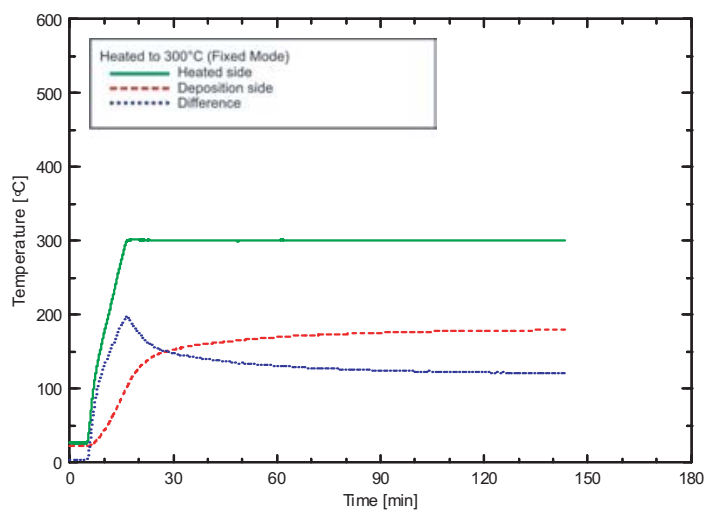

Fig. 5. Heating to $300{ }^{\circ} \mathrm{C}$

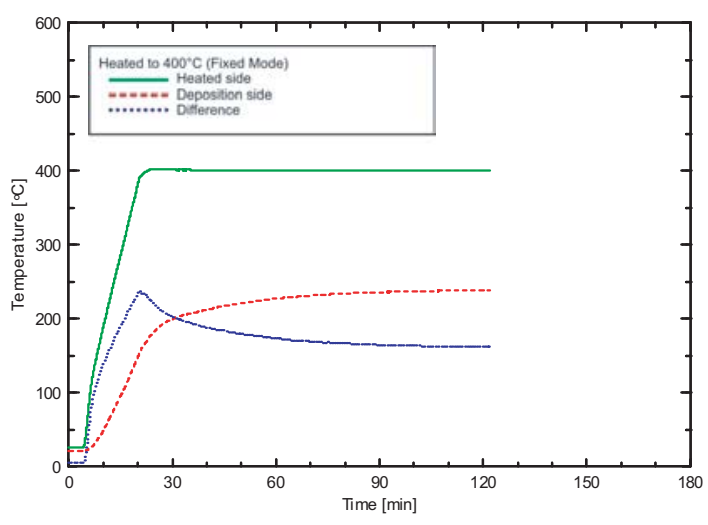

Fig. 6. Heating to $400{ }^{\circ} \mathrm{C}$

\subsection{Deposition of $\mathrm{Cu}$ and $\mathrm{Sn}$ Films for Friction Tests}

Before starting the deposition of copper and tin layers for friction tests, the device for thickness monitoring was calibrated. This means that the copper layer on the silicon substrate as well as the tin layer on the silicon substrate were deposited. In cooperation with Kawamura Research Laboratories the $\mathrm{Cu}$ and Sn layer thickness was measured with a VK-8500 laser microscope. When the measurement was over the calibration/tooling numbers for $\mathrm{Cu}$ and Sn were calculated and set as the thickness reference into the monitor device.

For experiments the thin $\mathrm{Sn}$ and $\mathrm{Cu}$ films were deposited on a prepared stainless steel substrate by a vacuum deposition method in the evaporating apparatus where the values for vacuum reached $10^{-5} \mathrm{~Pa}$. The deposited metals, i.e. $\mathrm{Sn}$ and $\mathrm{Cu}$ were evaporated from separate crucibles (Figure 2). The copper layer of $2.0 \mu \mathrm{m}$ thickness used as an inter-metallic layer was deposited as the first layer to the substrate. After a cooling period of 4 hours the deposition process of the tin layer followed.

There were two different thicknesses of the Sn layer applied: one being $1.0 \mu \mathrm{m}$ thick and another being $2.0 \mu \mathrm{m}$ thick. For both film thicknesses the deposition started at a normal room temperature and such specimens are referred to as no-heated. For the specimens referred to as heated, the substrates were heated up to $300{ }^{\circ} \mathrm{C}$, measured on the heated side before the deposition started.

\section{Results and discussion}

The experimental results aimed at determination of lifetime and friction behaviour of the tested pairs in dependence on the film thickness and based on heated and no-heated substrates before the thin layer deposition are shown in Figs. 7 - 10.

Figure 7 shows two typical results of the test performed with the heated specimen (tin film thickness of $1(\mathrm{~m})$. The value of the coefficient of friction developed in a very different way. It can be easily seen that for the same experimental conditions the coefficient of friction reached the values within the range of $\mu=0.2$ to 0.7 . Lifetime of the friction pair is also remarkably different and varies from several minutes to tens of hours.
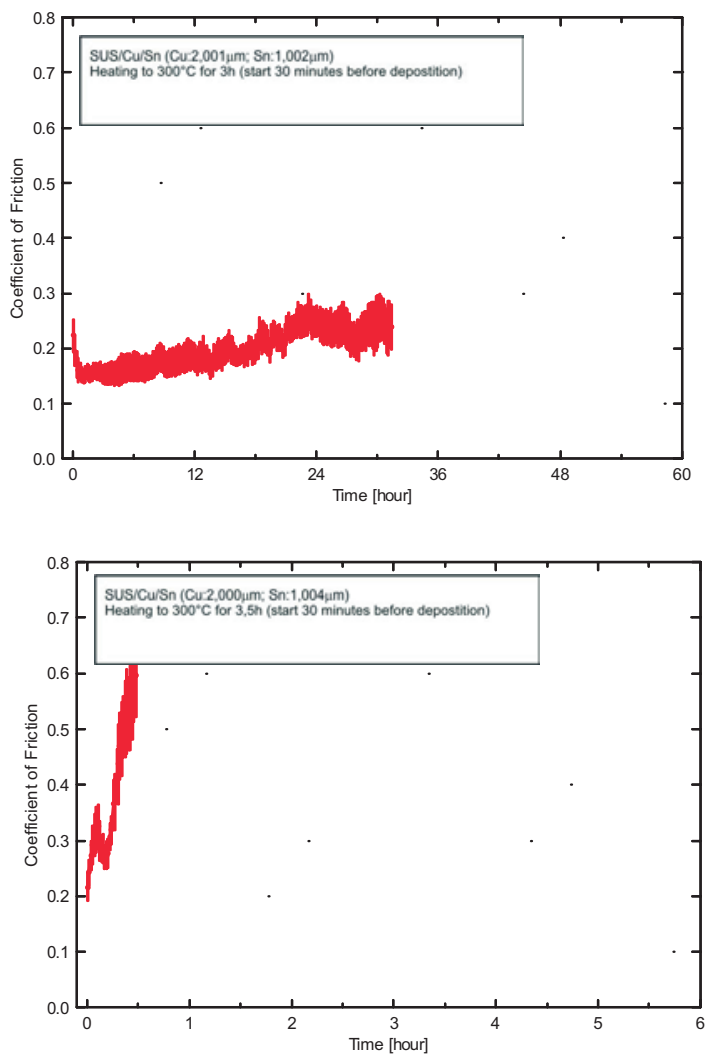

Fig. 7. Friction tests of heated specimens: $\mathrm{Cu}$ being $2.0 \mu \mathrm{m}$ and Sn being $1.0 \mu \mathrm{m}$ thick 
The friction behaviour of the tin film $2 \mu \mathrm{m}$ thick is plotted in Fig. 8. After the initial phase the friction coefficient slightly decreased to the values $\mu=0.12-0.15$ and remained nearly constant for the whole testing time.

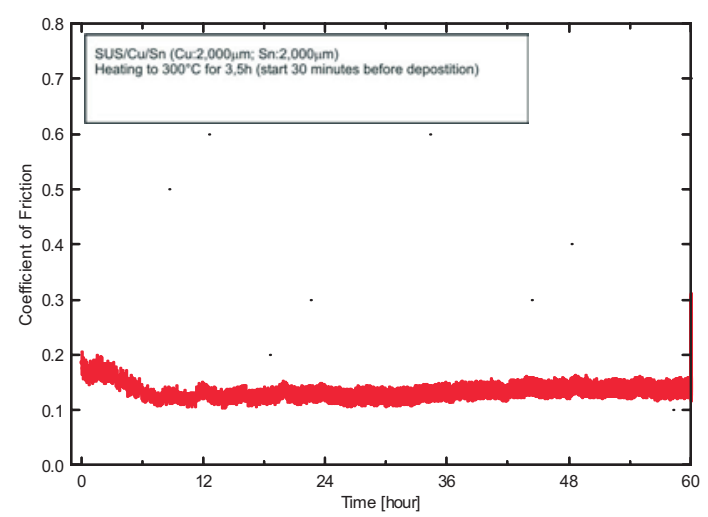

Fig. 8. Friction tests of heated specimens: Cu being $2.0 \mu \mathrm{m}$ and Sn $2.0 \mu \mathrm{m}$ thick

The experimental results for friction pairs composed of noheated specimens of $\mathrm{Cu} 2.0 \mu \mathrm{m}$ thick and $\mathrm{Sn} 1.0 \mu \mathrm{m}$ or $2.0 \mu \mathrm{m}$ thick are shown in Figures 9 and 10 respectively. For all the tested pairs there is a remarkable difference in lifetime. The same conclusion is valid for the level of friction $\mu=0.1$ to 0.3 , which was almost unstable with an increasing tendency within 12 hours of testing.

An interesting similarity with Fig. 7 can be seen in Fig. 10, which shows two typical results of the test performed with the noheated specimen. The values of the friction coefficient do not vary significantly but it can be easily seen that for the same experimental conditions the lifetime of the friction pair is remarkably different.

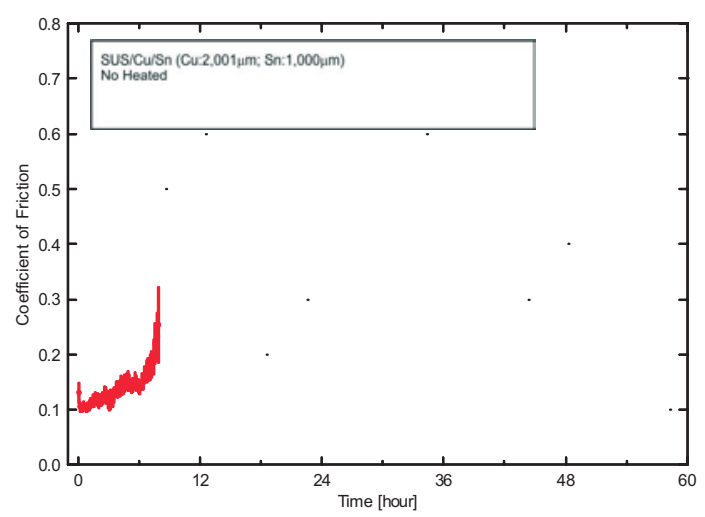

Fig. 9. Friction tests of no-heated specimens: $\mathrm{Cu}$ being $2.0 \mu \mathrm{m}$ and Sn being $1.0 \mu \mathrm{m}$ thick
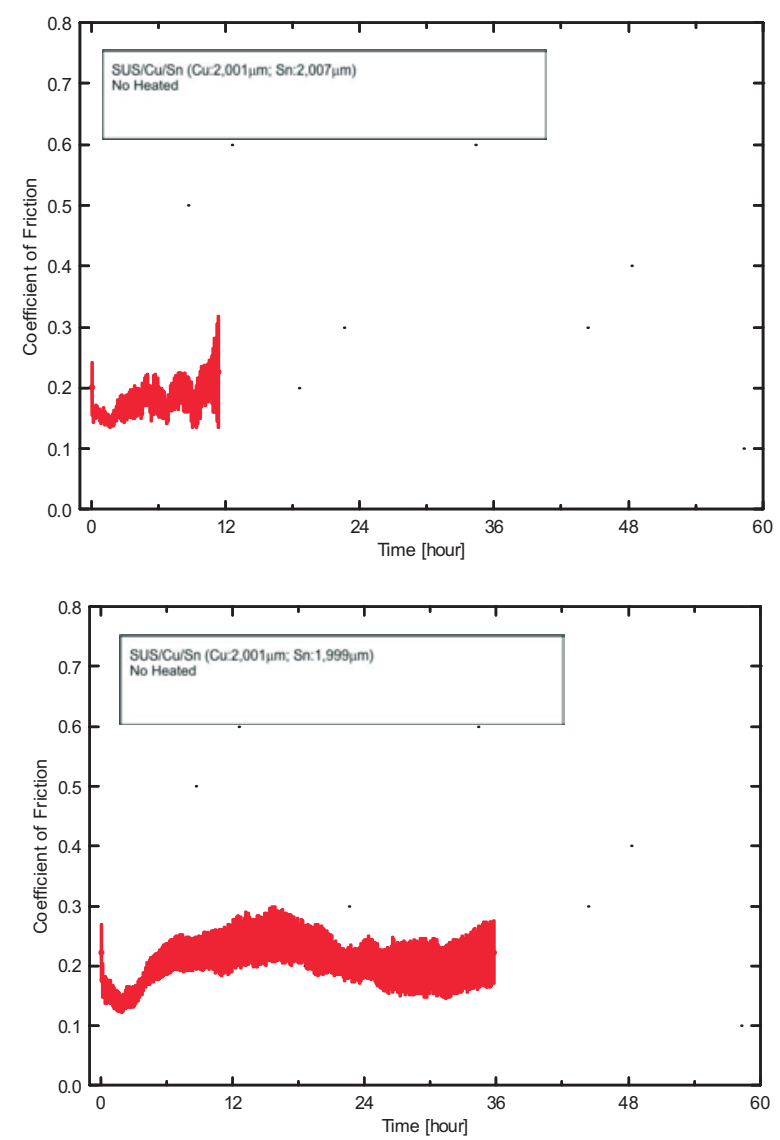

Fig. 10. Friction tests of no-heated specimens: $\mathrm{Cu}$ being $2.0 \mu \mathrm{m}$ and Sn being $2.0 \mu \mathrm{m}$ thick

\section{Conclusions}

Frictional properties and their influence on lifetime of friction pairs with thin tin films deposited on a copper interlayer with a constant thickness of $2.0 \mu \mathrm{m}$ on a stainless steel substrate were investigated. For frictional properties the thinner tin films generally showed higher values for the heated specimens. For the noheated specimens the values oscillated around $\mu=0.2$.

However, lifetime grows with an increasing thickness of a Sn layer. Considering also the heating of the substrate, in the case of heated specimens the lifetime is longer than for the no-heated ones.

The difference in lifetime for both types of specimens, i.e. with the heated and no-heated substrate as referred to in Figs. 7 10 will need more experimental investigation. Intermetallic compounds between copper and tin (mostly there are two kinds of intermetallic compounds, Cu6Sn5 and $\mathrm{CuSn} 3$ ) emerging during the deposition phase could be responsible for this phenomenon. 


\section{References}

[1] BHUSHAN, B. AND GUPTA, B. K.: Materials, coatings, and surface treatments, Handbook of Tribology, McGraw-Hill, Inc., 1991

[2] URAKAZE, K., DZIMKO, M., UEMURA, M.: Observation of the friction behaviour between coated and non coated silicon wafers and steel balls under extremely low loads, In: Proceedings of the international Tribology Conference, Yokohama 1995

[3] DZIMKO, M., URAKAZE, K., HOSOI, N., UEMURA, M.: Tribological properties of silicon blades coated with thin Pb-Sn films, Quarterly Journal SCIENCE VISION, July-September 1996, pp. 64 - 70, Pakistan

[4] TAKEICHI, Y., ARIGA, N., LI, C. S., UEMURA, M., DZIMKO, M.: The thickness effect of copper interlayer on frictional properties of lead-tin film, Applied Mechanics and Engineering, 1999, vol. 4 pp. 189 - 194.

UNIVERSITY OF ZILINA

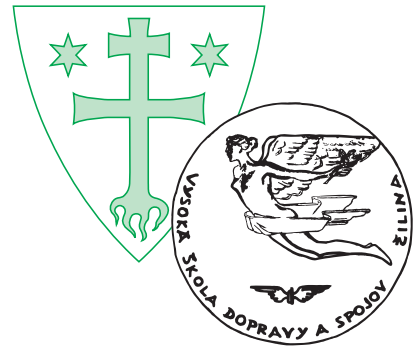

UNIVERSITY OF ZILINA

\section{TRANSCOM 2005}

6-th EUROPEAN CONFERENCE OF YOUNG RESEARCH AND SCIENCE WORKERS IN TRANSPORT AND TELECOMMUNICATIONS

under the auspices of

Minister of the Slovak Ministry of Education

Rector of the University of Zilina

ZILINA 27. - 29. 6.2005, SLOVAK REPUBLIC

CONFERENCE LANGUAGES

English, German

CONFERENCE FEE

30,-EUR for foreign participants

1.000 ,-Sk for participants from

the Slovak Republic

500,-Sk for postgraduate

students from the Slovak universities

CONTACT ADDRESS

University of Zilina Ing. Helena Vrablova Univerzitna 8215/1 01026 Zilina Slovak Republic

Tel.++421-41-5135141 fax: ++421-41-5135052 e-mail: vrablova@nic.utc.sk

Further information on the Conference can be found at www address: www.transcom2005.sk 